How do the performance and well-being of students with an immigrant background compare across countries?






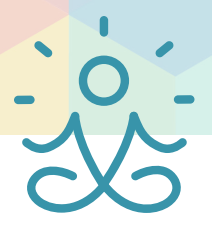

\section{How do the performance and well-being of students with an immigrant background compare across countries?}

- In 2015, 23\% of 15-year-old students in OECD countries were either foreign-born or had at least one foreignborn parent, on average across OECD countries. This share had increased by six percentage points, on average, between 2003 and 2015.

- On average across OECD countries, first-generation immigrants (foreign-born children of foreign-born parents) scored lower in academic subjects and reported a weaker sense of belonging at school, less satisfaction with life, and greater schoolwork-related anxiety than did students without an immigrant background. By contrast, more first-generation immigrant students than students without an immigrant background reported high motivation to achieve.

- Academic underperformance among immigrant students is particularly pronounced in Austria, Belgium, Denmark, Finland, Germany, Iceland, Luxembourg, Slovenia, Sweden and Switzerland.

- In the Slovak Republic and Spain immigrant students are considerably less likely to report a strong sense of belonging at school; in France, Mexico, the Slovak Republic and Spain students with an immigrant background are considerably less likely to report being satisfied with their life; and in Austria, Finland, Luxembourg and Switzerland, they are considerably more likely than native students to report high levels of schoolwork-related anxiety.

Migration flows are profoundly changing the composition of classrooms. PISA reveals that in 2015, almost one in four 15-year-old students in OECD countries reported that they were either foreign-born or had at least one foreign-born parent - and that is without counting the tens of thousands of refugees and asylum seekers who most recently arrived in many of the countries that participated in PISA. In Switzerland and Luxembourg, more than one in two 15-year-old students reported that they were either foreign born or had at least one parent who was. Between 2003 and 2015, the share of students who had either migrated or who had a parent who had migrated across international borders grew by six percentage points, on average across OECD countries.

Migration flows from several decades ago still loom large. Of all groups of students with an immigrant background, defined here as either being foreign-born or having at least one foreign-born parent, the share of second-generation immigrant students (native-born children of foreign-born parents) grew most rapidly (by 3 percentage points) on average across OECD and EU countries between 2003 and 2015. Native-born students with a mixed heritage, i.e. students who were born in the country in which they sat the PISA test and have one native- and one foreign-born parent, grew by 2 percentage points, on average, across OECD countries and by 3 percentage points across EU countries. Migration waves after 2000, which are reflected in the share of foreign-born students, account only for a one percentage-point increase, on average, across both OECD and EU countries. In 2015, recent arrivals - foreign-born students who settled in the host country at or after the age of 12 - represented about one-third of all first-generation immigrant students, on average.

These averages mask large differences across countries. For example, in Ireland the share of first-generation immigrant students increased by as much as nine percentage points between 2003 and 2015; and among OECD countries, the share of recently arrived first-generation immigrant students was particularly large in Australia, Canada, Luxembourg and New Zealand.

The ability of societies to preserve social cohesion in the presence of large migration flows depends on their capacity to integrate immigrants. Education can help immigrants acquire skills and contribute to the host-country economy; it can also foster immigrants' social and emotional well-being and sustain their motivation to participate in the social and civic life of their new communities - and, by doing so, help them integrate more easily. But ensuring that students with an immigrant background have good well-being outcomes represents a significant challenge, because many immigrant or mixed-heritage students must overcome the adversities associated with displacement, socio-economic disadvantage, language barriers and the difficulty of forging a new identity all at the same time. 


\section{Percentage of students with an immigrant background}

Percentage of students that are either first-generation immigrants, returning foreign-born immigrants, second-generation immigrants, or native students of mixed heritage, by country

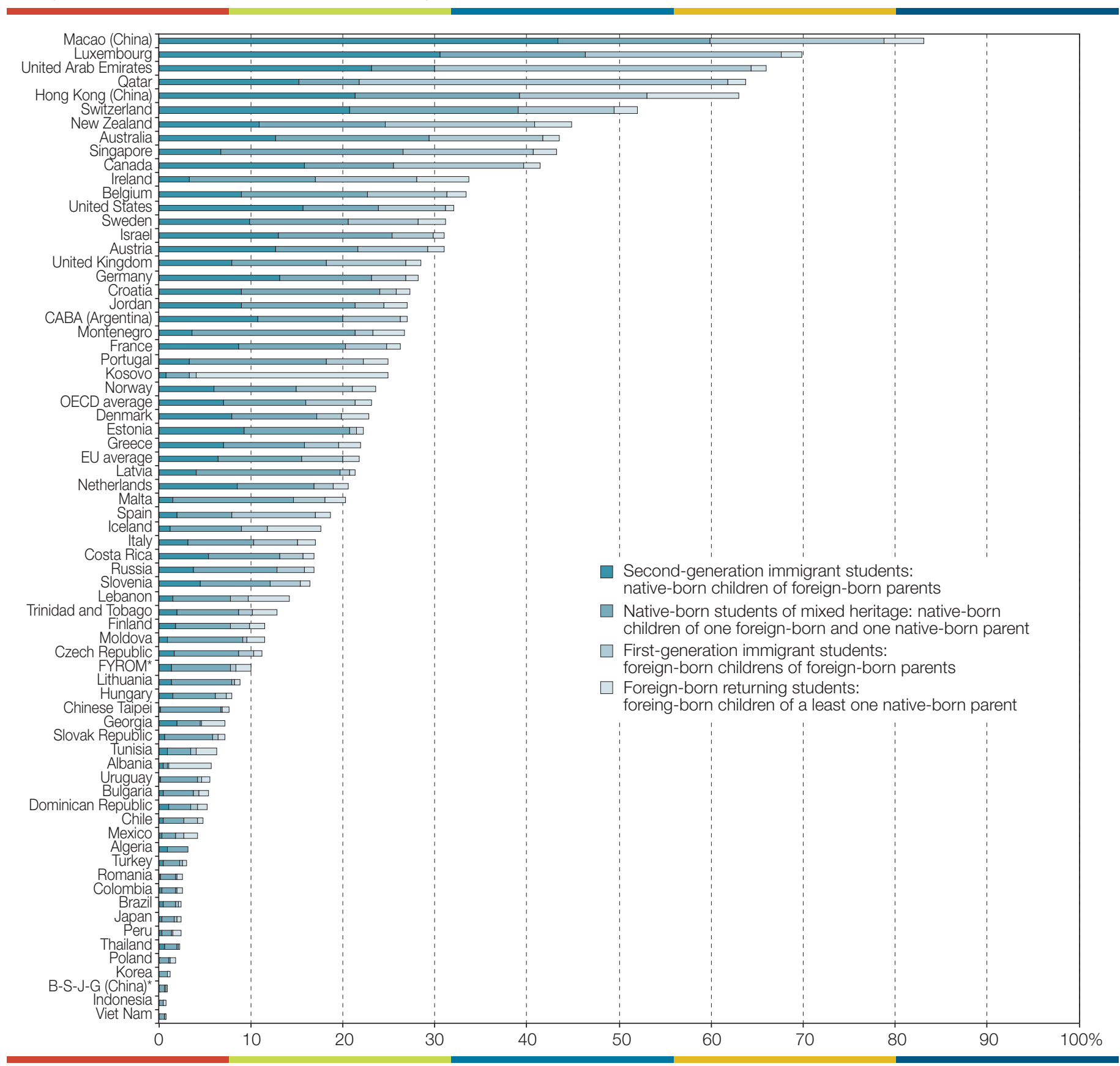

${ }^{*}$ B-S-J-G (China) refers to the four PISA-participating Chinese provinces: Beijing, Shanghai, Jiangsu and Guangdong. FYROM refers to the Former Yugoslav Republic of Macedonia.

Countries and economies are ranked in descending order of the percentage of students with an immigrant background.

Source: OECD (2018), The Resilience of Students with an Immigrant Background: Factors that Shape Well-Being, Table 3.2, based on PISA 2003 and 2015 Databases.

The capacity of students with an immigrant background to overcome these hardships and be resilient is reflected not only in their ability to attain baseline levels of academic proficiency, but also in their sense of belonging at school, their satisfaction with life, their level of schoolwork-related anxiety and their motivation to achieve. These five indicators represent key dimensions of well-being measured by PISA in 2015. 


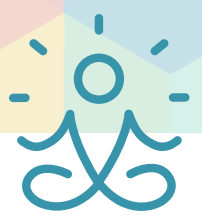

Trends between 2003 and 2015 in the percentage of native-born students with native-born parents

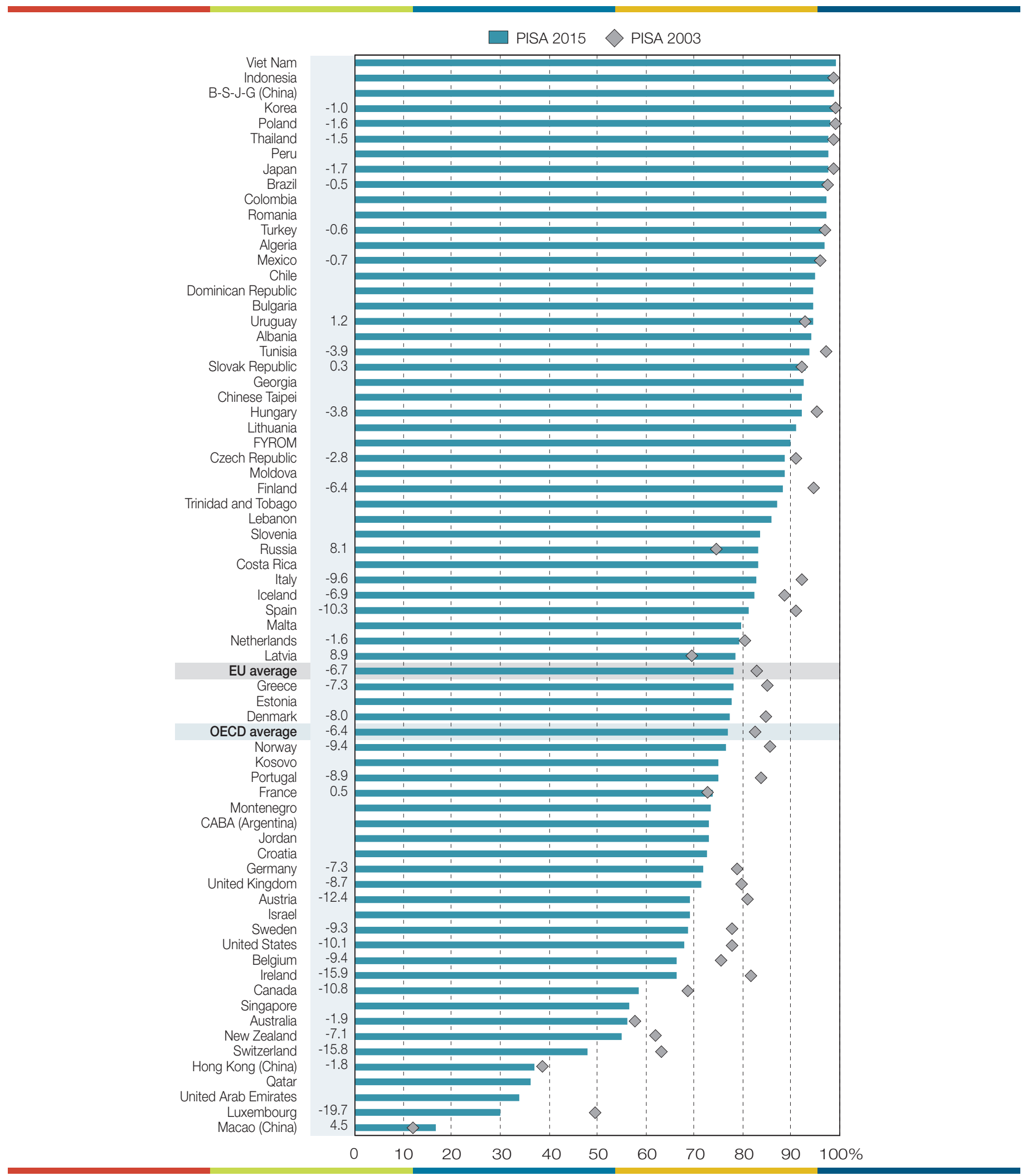

Notes: Students without an immigrant background are defined as native-born students with native-born parents. Only countries/economies that participated in PISA 2015 are shown.

Statistically significant differences between PISA 2015 and PISA 2003 are shown next to country/economy names.

Countries and economies are ranked in descending order of the percentage of native-born students with native-born parents in 2015.

Source: OECD (2018), The Resilience of Students with an Immigrant Background: Factors that Shape Well-Being, Table 3.2, based on PISA 2003 and 2015 Databases. 
Students with an immigrant background tend to underperform in school. This is particularly true of first-generation immigrant students (foreign-born students of foreign-born parents). On average across OECD countries, as much as 51\% of first-generation immigrant students failed to reach baseline levels of academic proficiency in reading, mathematics and science (PISA Proficiency Level 2 or above), compared to $28 \%$ of students without an immigrant background who failed to reach those levels. Similar differences are observed in most other well-being outcomes as well: $41 \%$ of first-generation immigrant students reported a weak sense of belonging at school, compared to $33 \%$ of students without an immigrant background; $31 \%$ of first-generation immigrant students reported low life satisfaction, compared to $28 \%$ of students without an immigrant background; and $67 \%$ of first-generation immigrant students reported high schoolwork-related anxiety, compared to $61 \%$ of students without an immigrant background.

Academic underperformance among immigrant students is particularly critical in Austria, Belgium, Denmark, Finland, Germany, Iceland, Luxembourg, Slovenia, Sweden and Switzerland. In these countries, native- or foreign-born students who have two foreign-born parents are more than twice as likely as students without an immigrant background to fail to achieve baseline academic proficiency.

But even in some countries where academic underperformance among students with an immigrant background is not as pronounced, the analysis shows that immigrant students suffer in other measures of well-being. In the Slovak Republic and Spain, for example, students with an immigrant background were considerably less likely to report a strong sense of belonging at school; in France, Iceland, Spain and the United Kingdom, immigrant students were considerably less likely

\section{Risks to well-being for students with an immigrant background OECD average}

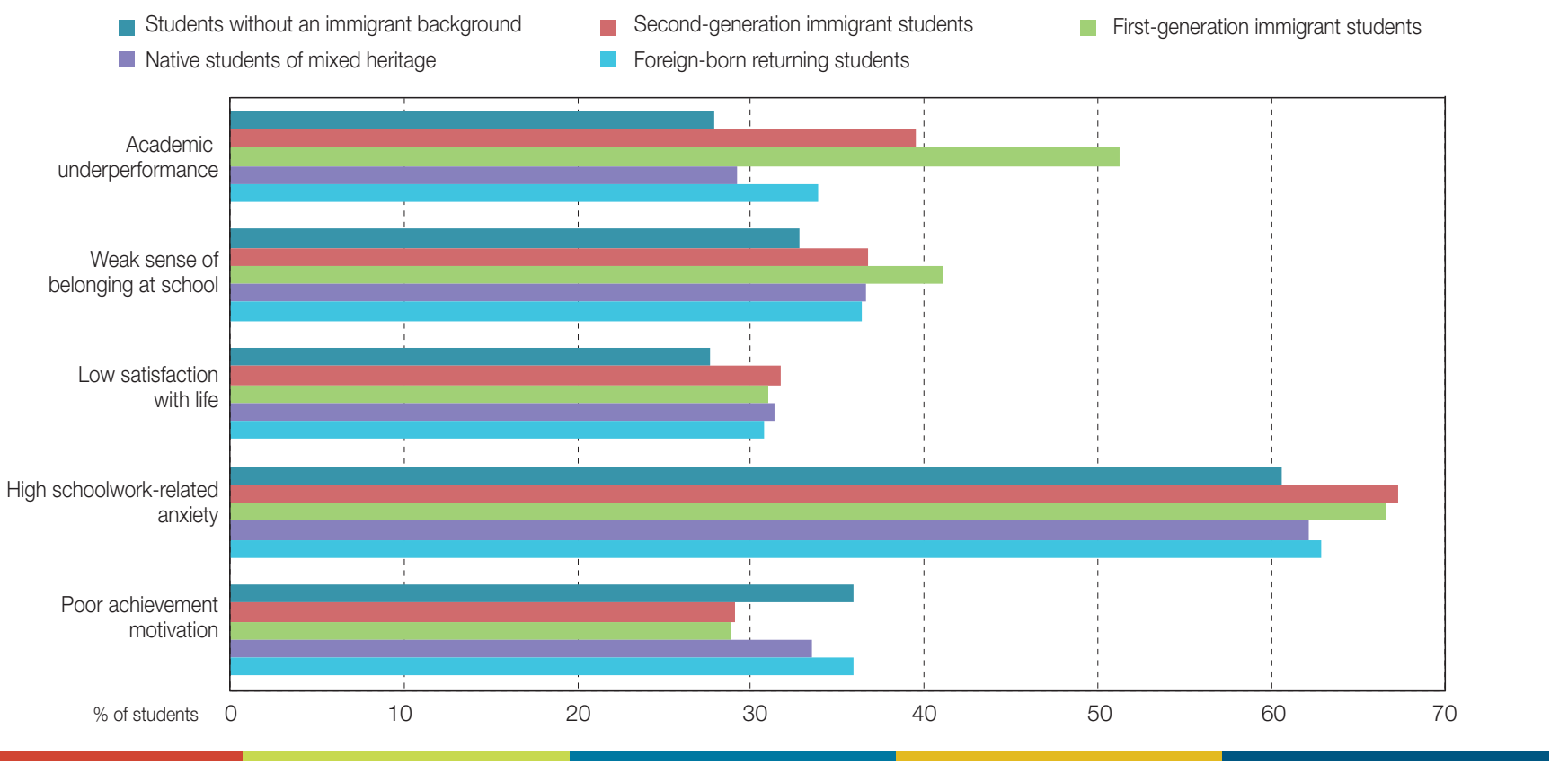

Notes: Differences in all outcomes between students without an immigrant background and all categories of students with an immigrant background are statistically significant, except for the difference in the percentage of students with poor achievement motivation between students without an immigrant background and returning foreign-born students.

Academic underperformance implies that a student failed to attained at least proficiency Level 2 in all three core PISA subjects: science, reading and mathematics.

Weak sense of belonging implies that a student reported that he or she "disagrees" or "strongly disagrees" with the statement "I feel like I belong at school" and "agrees" or "strongly agrees" with the statement "I feel like an outsider at school". Low satisfaction with life implies that a student reported a life satisfaction of 6 or less on a $0-10$ scale.

High school-work related anxiety implies that a student reported that he or she "agrees" or "strongly agrees" with the statements "I often worry that it will be difficult for me taking a test" and "Even if I am well prepared for a test, I feel very anxious".

Poor achievement motivation implies that a student "disagrees" or "strongly disagrees" with the statement "I want to be the best, whatever I do".

Source: OECD (2018), The Resilience of Students with an Immigrant Background: Factors that Shape Well-Being, Table 1.1, based on the PISA 2015 Database. 




to report being satisfied with their life. In Austria, Finland, Luxembourg and Switzerland, they were considerably more likely than native students to report high levels of schoolwork-related anxiety. In virtually all countries, students with an immigrant background expressed greater motivation to achieve. Only in Israel and Mexico were immigrant students less likely to report high achievement motivation than students who had no direct experience of migration.

Overall, countries differ greatly in the risks to well-being that most affect immigrant students. For example, while immigrant students in Belgium, Denmark, Germany and Slovenia appear to be particularly at risk of poor academic proficiency, but fare relatively well in other aspects of well-being, students in Ireland, the Slovak Republic and Spain appear to be particularly at risk of having only a weak sense of belonging at school and of reporting low satisfaction with life.

Socio-economic disadvantage and language barriers are two of the greatest obstacles to integrating students with an immigrant background. For example, differences in socio-economic status explain over one-fifth of the gap in the likelihood of attaining baseline levels of academic proficiency between immigrant students and students without an immigrant background, on average across OECD countries. Similarly, immigrant students in OECD countries who do not speak the language of assessment at home are around eight percentage points less likely than native-speaking immigrant students to be academically resilient. But in some countries, the education system and host communities help students with an immigrant background overcome disadvantage and enable them to capitalise on their high motivation to succeed and flourish.

\section{The bottom line}

Education systems, schools and teachers can play a significant role in helping students with an immigrant background integrate into their communities, overcome adversity and build their academic, social, emotional and motivational resilience. Providing early assessments of language and other skills; offering targeted language training; building a diversity-aware teaching force that can support all learners; providing additional support to disadvantaged students and schools; implementing effective anti-bullying programmes; ensuring the availability of and participation in extracurricular activities; and engaging parents can improve the well-being of students with an immigrant background, in all its facets. 



\section{For more information}

Contact: Francesca Borgonovi (Francesca.Borgonovi@OECD.org )

See: OECD (2018), The Resilience of Students with an Immigrant Background: Factors that Shape Well-Being, OECD Publishing, Paris, http://dx.doi.org/10.1787/9789264292093-en.

Coming next month: How did Internet use change between 2012 and $2015 ?$

This paper is published under the responsibility of the Secretary-General of the OECD. The opinions expressed and the arguments employed herein do not necessarily reflect the official views of OECD member countries.

This document, as well as any data and map included herein, are without prejudice to the status of or sovereignty over any territory, to the delimitation of international frontiers and boundaries and to the name of any territory, city or area.

The statistical data for Israel are supplied by and under the responsibility of the relevant Israeli authorities. The use of such data by the OECD is without prejudice to the status of the Golan Heights, East Jerusalem and Israeli settlements in the West Bank under the terms of international law.

This work is available under the Creative Commons Attribution-NonCommercial-ShareAlike 3.0 IGO (CC BY-NC-SA 3.0 IGO). For specific information regarding the scope and terms of the licence as well as possible commercial use of this work or the use of PISA data please consult Terms and Conditions on www.oecd.org.

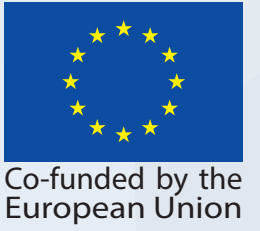

